\title{
Effects of a Hearing Aid on Speech Perception and Quality of Life of the Elderly with Hearing Loss
}

\author{
Mee Hye Park' , Ju Hong Park² \\ ${ }^{1}$ SLP \& Audiology Kaya University, Gimhae, Korea \\ ${ }^{2}$ Graduate School of Public Health, Kaya University, Gimhea, Korea \\ 보청기 착용이 노인성 난청인의 어음지각과 삶의 질에 미치는 효과 \\ 박 미 혜'박 주 홍 ${ }^{2}$ \\ 가야대학교 언어치료청각학과 ${ }^{1}$, 가야대학교 보건대학원 언어병리학과 ${ }^{2}$
}

\begin{abstract}
Purpose: This study aims to investigate the effects of wearing a hearing aid on the speech perception and hearing handicap index of the elderly with presbycusis. Methods: This study examined whether there were differences in the scores of consonant and sentence perception and hearing handicap index according to age and degree of hearing loss with 34 the elderly with presbycusis. Results: First, there was a significant difference in consonant perception before and after wearing a hearing aids. However, there was a significant difference in consonant perception according to the degrees of hearing loss while there was no significant difference according to age. Second, there was a significant difference in the score of sentence perception before and after wearing a hearing aid. In addition, there was a significant difference in the score of sentence perception according to age and the degree of hearing loss, too. Third, there was a significant difference in hearing handicap index before and after wearing a hearing aid. In addition, there was a significant difference in hearing handicap index according to age and the degree of hearing loss. Conclusion: It is noted that wearing a hearing aid has positive effects on speech perception and hearing handicap index of the elderly with presbycusis, and it is concluded that even in patients with presbycusis, the effects of hearing aids increase in those who are relatively younger with less hearing loss.
\end{abstract}

Key Words: Hearing aid, Presbycusis, Speech perception, Quality of life.

\section{INTRODUCTION}

경제 수준의 향상, 의료기술 발전 등으로 인해 인간의 평균 수 명이 길어져 인구의 노령화는 오늘날 모든 국가가 고민하는 문 제가 되었다. 우리나라의 경우도 매우 빠른 속도로 고령 사회에 진입하고 있어 많은 영역에서 노인들이 갖는 문제에 대해 관심 을 갖고 있다. 노령 인구가 겪는 문제 가운데 어음 청취 및 의사 소통의 불편 등을 일으키는 노인성 난청(presbycusis)을 빠뜨릴 수 없다. 노인성 난청은 노화로 인해 발생하는 전형적인 퇴행성 변화에 의한 청력손실로 의사소통에 필수적인 어음에 대한 지 각력을 감소시킨다. 특히 노인성 난청은 $1 \mathrm{kHz}$ 이상의 주파수
대역에서 심한 청력손실이 발생하는 것이 특징으로(Mościcki et al., 1985), 연령에 따라 점차 청력손실 정도가 심해지고 단어 인지도 점수도 점차 낮아진다(Baek et al., 2013). Gates \& Mills (2005)에 의하면 청력손실이 2 4 kHz까지 진행되면 무성자음 $/ \mathrm{t}, \mathrm{p}, \mathrm{k}, \mathrm{f}, \mathrm{s}, \mathrm{ch} /$ 를 이해하기 어려워지기 때문에 대부분의 의사 소통 상황에서 곤란을 겪게 된다고 한다. 어음지각에 있어 노인 성 난청인의 가장 일반적인 호소는 들을 수 없는 것이 아니라 들어도 무슨 말을 하는지 이해할 수 없다는 점이다. 흔히 노인 성 난청인은 '식사를 '인사'로, '자다를 '오다'로 '사람'을 '바람'으 로 혼동하며, 또는 '댁'과 ‘백', '귤'과 '굴' 혹은 '걸을 혼동한다. 고 주파수 대역의 손실로 시작된 노인성 난청은 점진적으로 낮은 
주파수로 확대되는데(Gates \& Mills, 2005), 저주파수 대역까지 청력손실이 확대되면 더욱 심한 어음지각의 어려움을 겪게 된다. 노인성 난청의 또 다른 문제는 정보 교환의 어려움으로 인해 외로움과 고립, 의존과 좌절 등의 이차적인 심리적, 사회적 문 제를 갖게 되어 삶의 질이 떨어진다는 것이다(Ciorba et al., 2012). Gates \& Mills(2005)는 난청이 개인의 심리·사회적 상 황에 미치는 부정적인 영향을 치료하지 않고 방치하면 사회적 고립감, 우울증 및 자존감 상실의 원인이 되며, 노인성 치매의 원인이 되기도 한다고 하였다. Lin et al.(2011)도 경도 난청으로 인한 치매 발병률이 정상인의 1.8 배에 이르고, 고도 난청이 되 면 4.94배로 높아진다고 지적하였다.

이러한 노인의 청력 문제를 해결하기 위한 가장 중요한 방법 은 보청기를 착용하는 것으로 보청기의 착용은 노인성 난청으 로 인해 겪는 의사소통의 문제를 감소시키고 이차적인 문제를 예방함으로써 궁극적으로는 삶의 질에 긍정적인 영향을 미칠 수 있다. Popelka et al.(1998)에 의하면 난청은 노인들의 기능 과 삶의 질에 심각한 영향을 주는 문제이지만 재활과 함께 보 청기를 사용하면 효과가 크다고 지적하였다. Shin(2013)은 노인 성 난청이 비가역적인 손상으로 일어난 현상이므로 대화가 가 능하도록 기능적 개선을 도모하는 것이 가장 중요하다고 지적 하며, 노인성 난청인에게 가장 효과적인 재활 치료방법은 보청 기 착용으로 특히 경도 및 중등도 노인성 난청에게 더욱 효과적 이라고 했다. Northern \& Beyer(1999)는 보청기 착용과 함께 청능 훈련을 실시하면 보청기만 착용하는 것보다 심리적인 면 에서 건강과 관련된 삶의 질에 대한 인식을 개선할 수 있어 더 욱 효과적이라고 밝히기도 했다. Acar et al.(2011)은 청력손실 이 있는 노년층들이 삶의 질을 향상시키기 위해서는 보청기를 착용하고 보청기에 적응해 나가는 것이 가장 훌륭한 해결책이 라고 지적하였다.

따라서 본 연구에서는 노인의 난청 문제를 해결하기 위한 방 법으로써 보청기의 착용이 의사소통에 매우 중요한 어음지각 력을 개선시키는지 알아보고, 청각장애지수의 변화를 통해 궁 극적으로 삶의 질을 개선시키는 효과가 있는지 알아보고자 했 다. 이를 위해 노인성 난청으로 진단받아 보청기를 착용하려고 하는 노인들에게 보청기 착용 전과 착용 후의 자음 및 문장 지 각력과 청각장애지수를 측정하여 비교해 보았다. 연구의 결과 는 노인성 난청인을 위한 청능 재활에 있어 보청기의 중요성을 뒷받침할 수 있는 자료로 활용될 것으로 판단된다.

\section{MATERIALS AND METHODS}

\section{연구 대상}

연구 대상은 경남 소재 이비인후과 난청 클리닉에서 의사로
부터 노인성 난청으로 진단받은 만 65 세 이상의 남녀 노인 34명 이다. 모두 순음청력검사에서 양측 귀에 대칭적 형태의 청력도 를 보이며, 외상이나 이독성 약물, 귀의 질환, 소음 노출, 귀 수 술 등과 같은 과거력이 없고, 기골도 역치 차이(air-bone gap)가 $10 \mathrm{~dB}$ 이내이며, 가족력이 없는 노인성 난청의 선정 조건을 충 족하는 노인이다.

순음청력검사(Aurical, GN Otometrics, Taastrup, Denmark) 를 실시하여 청력도를 확인하고, 중도(moderate, $41 ~ 55 \mathrm{~dB}$ ), 중 고도(moderate-severe, 56 70 dB) 및 고도(severe, 71 90 dB) 의 집단으로 나누었으며(6분법), tympanometry (GSI 39, Grason Stadler, Eden Prairie, MN, USA)를 실시하여 모두 A type의 정상 고막운동도를 가진 것을 확인하였다. 평균 연령은 74세(65 84세)이며, 평균 순음청력역치는 $61 \mathrm{~dB} \mathrm{HL}$ 이고(51 81 $\mathrm{dB})$, 모두 보청기를 처음 착용하는 노인들로 편측만 보청기를 착용하였다. 구체적인 연구 대상의 청각적 정보는 Table 1에 제 시하였다. 연구 대상 모두 연구 참여 전 연구의 목적 및 절차에 대한 설명을 듣고 연구 참여 동의서에 서명하였다.

\section{연구 도구}

\section{한국어 자음지각검사}

자음지각 능력을 측정하기 위해서는 한국어 자음지각검사 (Korean Consonant Perception Test, KCPT) (Kim et al., 2011) 를 사용하였다. $\mathrm{KCPT}$ 는 청각장애인의 자음지각력을 평가하는 것으로 $\mathrm{A}$ 와 B 목록 두 개의 동형검사로 이루어져 있다. 초성검 사(100문항)와 종성검사(50문항)로 구분되며, 문항당 네 개의 단음절 낱말이 배열되어 있어 제시 자극을 듣고 네 개 중 하나 를 선택하게 한다. 본 연구에서는 A 목록을 사용하였다. 전체 문항 중 정반응한 문항 수를 제외하고 오반응이나 무반응 문항 수를 계산하여 $\mathrm{KCPT}$ 점수를 산출하였다.

\section{서울대학교 병원-성인용 문장검사}

문장지각 능력을 측정하기 위해서는 서울대학교병원-성인용 문장검사(Seoul National University Hospital-Sentence test for Adult, SNUH-S-A) (The Korean Audiology Society,

Table 1. Auditory characteristics of subjects

\begin{tabular}{llcc}
\hline Variables & \multicolumn{1}{c}{ Group } & Frequency & $\%$ \\
\hline Age & $65-74$ & 16 & 47.1 \\
& $75-84$ & 18 & 52.9 \\
Hearing & Moderate $(41-55 \mathrm{~dB})$ & 12 & 35.3 \\
level & Moderate-severe $(56-70 \mathrm{~dB})$ & 14 & 41.2 \\
& Severe $(71-90 \mathrm{~dB})$ & 8 & 23.5 \\
& Total & 34 & 100.0 \\
\hline
\end{tabular}


2015)를 사용했다. 이는 난청 성인의 일상생활에서의 문장 수 준 지각 능력을 측정하기 위해 개발된 평가 도구로 청각적 수행 력의 진전을 확인하는 데 사용된다. SNUH-S-A는 7개의 검사 목록으로 구성되어 목록마다 50개의 핵심 단어로 이루어져 있 다. 문장을 대상에게 처음부터 끝까지 한 번만 들려주고 전체 문장을 따라 말하게 하거나 일부라도 들은 것을 따라 말하게 한다. 청각적 단서(Auditory Only)만 제시하는 상황에서 실시 하고 정반응 단어 수를 계산하여 얻은 점수에 대해 백분율을 산출하였다.

\section{청각장애지수}

연구 대상의 삶의 질을 측정하기 위해서는 한국 노인성 난청 의 청각장애지수(The Korean Hearing Handicap Inventory for the Elderly, KHHIE) (Ku \& Kim, 2000)를 사용하였다. KHHIE는 난청인의 사회활동이나 심리적 측면에 미치는 영향 을 측정하는 것으로 보청기 착용 전후의 효과를 측정하기 위해 주로 사용된다. KHHIE는 사회적/상황적(social/situational) 측 면(12문항), 심리적(emotional) 측면(13문항)으로 총 25문항으 로 구성되어 있다. 모든 문항에 대해 항상 그렇다(4점), 때때로 그렇다(2점), 그렇지 않다(0점)로 평가한다. 점수는 0점에서 100 점까지 높을수록 청각장애지수가 높고, 난청으로 인한 일상생 활의 곤란이 증가한다고 해석한다.

\section{측정방법}

보청기 착용 전과 후의 어음지각검사는 방음 부스 안에서 대 상자의 전방으로부터 $45^{\circ}$ 방위각으로 $1 \mathrm{~m}$ 의 거리에 스피커를 위치시키고 이를 통해 쾌적역치 강도 수준(most comfortable level)에서 실시하였다. 개인별 쾌적역치 강도 수준은 순음청력 역치에 $30 \mathrm{~dB}$ 을 증가시킨 강도에서 대상자에게 "제 말소리가 편안하게 들리나요?”라고 질문을 하고 2회 이상 편안하다고 반 응하는 강도를 개인의 쾌적역치 강도 수준으로 채택하였다. $\mathrm{KCPT}$ 와 SNUH-S-A는 모든 문항을 1회 제시한 다음 반응 문 항을 지적하거나 따라 말하도록 하였으며, KHHIE는 직접 읽 고 반응하거나 글을 모르거나 이해하지 못한 경우는 연구자가 직접 읽어주고 대답하도록 하였다.

\section{자료 처리}

측정된 자음 및 문장지각점수 그리고 청각장애지수에 대해 보청기 착용 전과 후에 차이가 있는지 알아보기 위해 기술통계 값을 제시하였으며, 집단 간 차이를 검증하기 위해서는 대응표 본 t-검정과 이원분산분석 및 사후분석을 실시하였다. 통계 처 리는 SPSS WINDOW 22.0 프로그램(IBM Corp., Armonk, $\mathrm{NY}, \mathrm{USA})$ 을 사용하여 분석하였다.

\section{RESULTS}

\section{보청기 착용 전 후의 자음지각점수}

연령 및 청력에 따른 보청기 착용 전과 후의 $\mathrm{KCPT}$ 점수에 대한 기술통계 값은 Table 2 와 같다. 평균 $\mathrm{KCPT}$ 점수는 착용 전 42.59( \pm 14.88 )에서 보청기 착용 후에는 26.88( \pm 12.30 )로 나타나 보청기 착용 전과 후의 $\mathrm{KCPT}$ 점수에는 유의미한 차이 가 있었다 $(\mathrm{t}=11.650, p<0.05)$. 변인별로 보면 연령에 따른 차 이는 나타나지 않았으나, 청력손실 정도에 따라서는 모든 집단 간에 유의미한 차이가 있는 것으로 나타났다 $(\mathrm{F}=26.404, p<$ 0.001).

\section{보청기 착용 전 · 후의 문장지각점수}

노인성 난청인의 보청기 착용 전과 후의 SNUH-S-A 점수는 Table 3과 같다. SNUH-S-A 점수는 착용 전에는 77.41( \pm 9.55), 보청기 착용 후에는 86.00( \pm 8.34)으로 유의미한 차이가 있는 것으로 나타났다 $(\mathrm{t}=-8.352, p<0.05)$. 연령 $(\mathrm{F}=5.537, p<$ $0.05)$ 및 청력손실 정도 $(\mathrm{F}=11.523, p<0.001)$ 에 따른 착용 전 과 후의 SNUH-S-A 점수에 대해 이원분산분석을 실시한 결 과 유의미한 차이가 나타났다. 평균 청력손실 중도 집단과 고도 집단 간, 그리고 중고도 집단과 고도 집단 간에 유의미한 차이 가 있었으나 중도 집단과 중고도 집단 간에는 나타나지 않았다.

Table 2. Descriptive statistics of Korean Consonant Perception Test score at the pre-test and post-test

\begin{tabular}{|c|c|c|c|c|}
\hline \multirow{2}{*}{ Variables } & \multirow{2}{*}{ Group } & \multirow{2}{*}{$\mathrm{n}$} & \multirow{2}{*}{$\begin{array}{c}\text { Pre } \\
\mathrm{M}(\mathrm{SD})\end{array}$} & \multirow{2}{*}{$\begin{array}{c}\text { Post } \\
\mathrm{M}(\mathrm{SD})\end{array}$} \\
\hline & & & & \\
\hline \multirow[t]{2}{*}{ Age } & $65-74$ & 16 & $40.06( \pm 14.96)$ & $23.19( \pm 11.47)$ \\
\hline & $75-84$ & 18 & $44.83( \pm 14.86)$ & $30.17( \pm 12.38)$ \\
\hline Hearing & Moderate & 12 & $29.00( \pm 12.40)$ & $17.67( \pm 11.76)$ \\
\hline \multirow[t]{2}{*}{ level } & Moderate-severe & 14 & $46.93( \pm 10.33)$ & $28.71( \pm 6.35)$ \\
\hline & Severe & 8 & $55.38( \pm 7.90)$ & $37.50( \pm 11.84)$ \\
\hline \multicolumn{2}{|c|}{ Mean } & & $42.59( \pm 14.88)$ & $26.88( \pm 12.30)$ \\
\hline
\end{tabular}

M: mean, SD: standard deviation

Table 3. Descriptive statistics of Seoul National University HospitalSentence test for Adult score at the pre-test and post-test

\begin{tabular}{|c|c|c|c|c|}
\hline \multirow{2}{*}{ Variables } & \multirow{2}{*}{ Group } & \multirow{2}{*}{$\mathrm{n}$} & \multirow{2}{*}{$\begin{array}{c}\text { Pre } \\
\mathrm{M}(\mathrm{SD})\end{array}$} & \multirow{2}{*}{$\begin{array}{c}\text { Post } \\
\mathrm{M}(\mathrm{SD})\end{array}$} \\
\hline & & & & \\
\hline \multirow[t]{2}{*}{ Age } & $65-74$ & 16 & $80.69( \pm 8.28)$ & $88.00( \pm 7.72)$ \\
\hline & $75-84$ & 18 & $74.50( \pm 9.87)$ & $84.22( \pm 8.67)$ \\
\hline Hearing & Moderate & 12 & $81.17( \pm 8.75)$ & $89.33( \pm 7.30)$ \\
\hline \multirow[t]{2}{*}{ level } & Moderate-severe & 14 & $79.21( \pm 6.93)$ & $87.43( \pm 7.16)$ \\
\hline & Severe & 8 & $68.63( \pm 10.07)$ & $78.50( \pm 7.83)$ \\
\hline \multicolumn{2}{|c|}{ Mean } & & $77.41( \pm 9.55)$ & $86.00( \pm 8.34)$ \\
\hline
\end{tabular}

M: mean, SD: standard deviation 
Table 4. Descriptive statistics of handicapped index at the pre-test and post-test

\begin{tabular}{|c|c|c|c|c|}
\hline \multirow{2}{*}{ Variables } & \multirow{2}{*}{ Group } & \multirow{2}{*}{$\mathrm{n}$} & Pre & Post \\
\hline & & & $\mathrm{M}(\mathrm{SD})$ & $\mathrm{M}(\mathrm{SD})$ \\
\hline \multirow[t]{2}{*}{ Age } & $65-74$ & 16 & $31.75( \pm 14.42)$ & $20.50( \pm 14.57)$ \\
\hline & $75-84$ & 18 & $43.56( \pm 15.62)$ & $33.67( \pm 16.83)$ \\
\hline Hearing & Moderate & 12 & $29.17( \pm 10.17)$ & $17.33( \pm 9.58)$ \\
\hline \multirow[t]{2}{*}{ level } & Moderate-severe & 14 & $38.71( \pm 15.40)$ & $28.29( \pm 15.58)$ \\
\hline & Severe & 8 & $50.00( \pm 17.43)$ & $41.25( \pm 19.06)$ \\
\hline \multicolumn{2}{|c|}{ Mean } & & $38.00( \pm 16.00)$ & $27.47( \pm 16.94)$ \\
\hline
\end{tabular}

M: mean, SD: standard deviation

\section{보청기 착용 전 - 후의 청각장애지수}

노인성 난청인의 보청기 착용 전과 후의 $\mathrm{KHHIE}$ 점수는 Table 4와 같다. 보청기 착용 전 $\mathrm{KHHIE}$ 점수는 38.00( \pm 16.00 ) 이었고, 보청기 착용 후에는 27.47( \pm 16.94$)$ 로 나타나 착용 전후 에 유의미한 차이가 나타났다( $\mathrm{t}=18.324, p<0.05)$. 연령( $\mathrm{F}=$ $11.067, p<0.001)$ 과 청력손실 정도 $(\mathrm{F}=11.469, p<0.001)$ 에 따 라서도 모든 집단 간에 유의미한 차이가 있는 것으로 나타났다.

\section{DISCUSSIONS}

본 연구는 보청기 착용이 노인성 난청인의 어음지각 및 삶의 질에 미치는 효과를 알아보기 위한 것이다. 이를 위해 노인성 난청인 34명을 대상으로 연령, 청력손실 정도에 따라 자음 및 문장지각점수, 그리고 청각장애지수를 보청기 착용 전과 후에 비교하였다. 본 연구의 주요 결과를 제시하고 논의하면 다음과 같다.

첫째, 보청기 착용 전과 후 노인성 난청인의 어음지각은 자음 지각 및 문장지각 모두 유의미한 차이가 있는 것으로 나타났 다. 이는 노인성 난청인이 보청기를 착용하는 것은 어음지각력 을 향상시키는 데 효과적이라는 것을 의미한다. 보청기 사용이 노인성 난청인의 어음지각에 효과가 있다는 것을 증명한 선행연 구로는 먼저, Lee(1996)의 연구가 있는데 이 연구에서는 보청기 를 착용한 2 3주 후에 단음절어의 이해도가 착용 전 평균 $28 \%$ 에서 착용 후 63\%로 향상되었다고 보고하였다. Woo(1999)는 노 인성 난청인의 경우 보청기를 착용하지 않으면 평균 $60 \%$ 이상 의 자음 오류를 나타내고 $40 \%$ 정도의 모음 오류를 보이지만 보청기를 착용하면 대부분 없어지거나 $10 \%$ 수준으로 감소한다 고 보고하고 있다. 일찍이 보청기가 청력손실이 있는 주파수대 역의 역치를 향상시켜 음향적 정보를 제공함으로써 어음지각 능력을 향상시킬 수 있다고 한 Pascoe(1975)의 지적을 다시 한 번 확인할 수 있다.

연령에 따라 살펴보면 자음지각에서는 연령에 따른 차이가 없었으나 문장지각에서는 유의미한 차이가 있었다. 연령이 낮
을수록 상대적으로 어음지각에 보청기가 미치는 효과가 클 것 으로 예상하였으나 자음지각에서는 차이가 없고 문장지각에서 는 유의미한 차이가 나타났다. Baek et al.(2013)은 연령을 55 64세, 65 74세, 75세 이상의 세 집단으로 나누어 단어인지도를 측정하였는데, 74 세 이하에서는 모두 단어인지도가 $80 \%$ 이상 정상 범위인 것으로 나타난 데 비해 75세 이상에서는 낮은 단 어인지도를 보인다고 했다. Shin \& Huh(2011)의 연구에서도 60대와 70대에서는 심한 청력역치의 변화가 없으나 80대 이상 이 되면 두드러지게 나타난다고 지적하고 있다. 이와 같이 많은 선행연구가 연령에 따라 역치가 상승하고 어음지각력의 차이가 분명하다고 지적한 데 비해 본 연구에서 부분적인 차이만이 나 타난 점은 65 74세 연령 집단에 포함된 일부 대상이 청력손실 을 보이는 주파수대역이 상대적으로 넓었기 때문이었던 것으로 보인다. 그러나 문장지각에서 나타난 차이에 대해서는 일반적으 로 문장을 지각할 때는 문장의 길이나 구조 복잡성이 연령이 많 을수록 더욱 큰 영향을 주기 때문으로 판단된다. 이와 관련하여 Jeon(2007)은 건청 노인에 비해 난청 노인은 문장의 길이가 길어 지면 문장 재인 능력이 낮아진다고 보고하고 있다. 일반적으로 노 년기의 정보처리는 속도와 단기기억과 같은 고인지 기능 과정의 변화로 인해 청각장애가 없어도 언어를 이해하는 데 어려움을 보 인다고 했다(Schneider et al., 2000). 이러한 경향은 건청 노인보 다 난청 노인에서 더욱 크게 나타난다는 점을 감안하면 본 연구 에서 나타난 문장지각의 차이를 설명할 수 있을 것이다.

청력손실 정도에 따라서는 자음지각이나 문장지각에서 모두 유의미한 차이가 있었다. 다시 말해 청력손실 정도가 클수록 자음이나 문장지각점수가 낮다는 것을 의미한다. Baek et al. (2013)의 연구에서도 난청 정도에 따라 단어인지도는 유의미하 게 차이가 있다고 지적하였으며, Lee et al.(2014)의 연구에서도 청력손실 정도가 경도인 경우 단어인지도점수가 $85.60 \%$, 중도 인 경우 $80.35 \%$, 중고도인 경우 $55.17 \%$, 고도인 경우 $41.43 \%$ 로 나타나 청력손실 정도가 심할수록 단어인지도점수가 감소한다 고 하였다. 마찬가지로 $\mathrm{Seo}(2015)$ 의 연구에서는 청력손실 정도 에 따른 어음인지도를 문장 따라하기 과제를 통해 측정한 결과, 경도 청력손실 집단은 $82.5 \%$, 중등도 집단은 $67.5 \%$ 로 난청 정 도가 심해질수록 점수가 감소한다고 보고했다. 임상적 견지에서 볼 때도 연령이 80대라 해도 중도 난청에 해당하는 노인의 자음 지각점수가 평균 이상으로 좋은 경우가 있고, 60대나 70대라 하 더라도 청력손실에 따라 자음지각점수의 분포가 다양하게 나타 나는 것을 쉽게 관찰할 수 있는데 이러한 점을 감안하면 어음지 각력은 연령보다는 청력손실 정도, 특히 고주파수 대역의 청력 손실 정도에 더 큰 영향을 받는다고 판단할 수 있다.

둘째, 보청기 착용 전과 후에 $\mathrm{KHHIE}$ 를 사용해 청각장애지 수를 산출하여 비교한 결과 청각장애지수는 착용 전에 비해 
착용 후에 유의미한 차이가 있는 것으로 나타났다. 또한 연령과 청력손실 정도에 따라서도 유의미한 차이가 있었다. 청각장애 지수를 개선하는 데 연령은 낮고 청력손실 정도가 적을수록 보 청기를 착용하는 것이 효과적이라는 것을 알 수 있었다.

Weinstein(1997)은 노인들이 사용하는 보청기의 긍정적인 효과에 대한 연구를 분석하고 보청기를 착용하면 사회적, 심리 적 영역에서 분명한 긍정적 결과가 나타나며, 보청기를 착용하 는 노인의 70 80\%는 보청기 사용과 관련된 청각장애지수가 상당히 감소한다고 하였다. 우리나라의 경우 KHHIE 기준을 제시하기 위해 한국 노인의 청력역치에 따른 장애 지수를 연구 한 Hong \& Lee(2002)에 따르면, KHHIE 점수는 청력역치가 상승할수록 청각장애지수가 높게 나타났다. 이는 청력손실 정 도가 클수록 일상생활에 있어 사회적, 정서적 영향을 크게 받는 것이라 할 수 있다. $\mathrm{Kim}(2009)$ 은 KHHIE를 사용하여 정상, 경 도에서 중도 청각장애로 구분하여 삶의 질에 대한 차이를 분석 한 결과, 보청기를 사용하지 않는 노인이 보청기를 사용하는 노 인보다 신체적 기능, 정신적 건강과 관련된 삶의 질이 유의하게 낮다고 했다. Shin(2011)은 청력손실의 정도가 노인 삶의 질에 미치는 영향을 평가하는 연구에서 난청 정도에 따른 난청장애 지수는 난청 정도가 심할수록 장애 지수가 높다고 하였다. 더욱 이 Lee et al.(2014)의 연구에서는 대화음의 강도나 배경소음 혹 은 다자간의 대화 등 일상생활에서 흔히 경험할 수 있는 의사소 통 상황에서 노인들은 젊은 사람에 비해 상대적으로 더 큰 어려 움을 겪으며, 청력손실 정도가 클수록 어려움의 정도가 증가한 다고 지적하고 있다. 이러한 선행연구들은 본 연구의 결과를 지 지하는 것으로 보청기를 착용하는 것은 청각장애지수의 변화를 주며 이에 따라 난청으로 어려움을 겪는 노인들의 삶의 질을 향 상시키는 데 효과적이라고 결론 지을 수 있다.

본 연구에서 나타난 보청기 착용 전후의 어음지각 및 청각장 애지수의 유의미한 차이는 측정 도구의 반복 측정에 의한 영향 이 있을 수 있음을 배제할 수 없다. 따라서 연구결과를 지나치 게 일반화하는 데 유의해야 하며 후속연구에서는 이 점을 감안 한 연구설계가 필요하다는 것을 연구의 제한점으로 지적한다.

중심 단어 : 보청기·노인성 난청·어음지각·삶의 질.

\section{REFERENCES}

Acar, B., Yurekli, M. F., Babademez, M. A., Karabulut, H., \& Karasen, R. M. (2011). Effects of hearing aids on cognitive functions and depressive signs in elderly people. Archives of Gerontology and Geriatrics, 52(3), 250-252.

Baek, H. J., Shim, H. Y., \& Kim, J. S. (2013). An analysis of characteristics for word recognition scores in geriatric hearing loss. Audiology, 9(1), 49-59.
Ciorba, A., Bianchini, C., Pelucchi, S., \& Pastore, A. (2012). The impact of hearing loss on the quality of life of elderly adults. Clinical Interventions in Aging, 7, 159-163.

Gates, G. A. \& Mills, J. H. (2005). Presbycusis. Lancet, 366(9491), 11111120.

Hong, B. N. \& Lee, J. H. (2002). Hearing threshold and hearing handicap of the elderly with presbycusis. Communication Sciences and Disorders, $7(1), 214-233$.

Jeon, J. Y. (2007). Effects of sentence length and structure on sentence recognition in the elderly (unpublished master's thesis). Hallym university, Chuncheon.

Kim, J. S., Shin, E. Y., Shin, W. H., \& Lee, K. D. (2011). Development of Korean Consonant Perception Test. The Journal of the Acoustical Society of Korea, 30(5), 295-302.

Kim, S. J. (2009). Hearing status, mood states and quality of life elderly (unpublished master's thesis). Hanyang University, Seoul.

Ku, H. R. \& Kim, J. S. (2000). Test-retest reliability of the Korean Hearing Handicap Inventory for the Elderly(KHHIE). Korean Journal of Communication Disorders, 5(1), 1-22.

Lee, J. H. (1996). The effects of hearing aids in presbycusis. Journal of Korea Gerontological Society, 16(2), 151-161.

Lee, J. Y., Hwang, H. K., \& Jang, H. S. (2014). Communication difficulties as a function of hearing sensitivity \& speech recognition in elderly with hearing loss. Journal of Rehabilitation Research, 18(1), 331-352.

Lin, F. R., Metter, E. J., O’Brien, R. J., Resnick, S. M., Zonderman, A. B., \& Ferrucci, L. (2011). Hearing loss and incident dementia. Archives of Neurology, 68(2), 214-220.

Mościcki, E. K., Elkins, E. F., Baum, H. M., \& McNamara, P. M. (1985). Hearing loss in the elderly: An epidemiologic study of the framingham heart study cohort. Ear and Hearing, 6(4), 184-190.

Northern, J. H. \& Beyer, C. M. (1999). Reducing hearing aid returns through patient education. Audiology Today, 11(2), 10-11.

Pascoe, D. P. (1975). Frequency responses of hearing aids and their effects on the speech perception of hearing-impaired subjects. The Annals of otology, Rhinology, and Laryngology, 84(5 pt 2 Suppl 23), 1-40.

Popelka, M. M., Cruickshanks, K. J., Wiley, T. L., Tweed, T. S., Klein, B. E., \& Klein, R. (1998). Low prevalence of hearing aid use among older adults with hearing loss: The epidemiology of hearing loss study. Journal of The American Geriatrics Society, 46(9), 1075-1078.

Schneider, B. A., Daneman, M., Murphy, D. R., \& See, S. K. (2000). Listening to discourse in distracting settings: the effects of aging. Psychology and Aging, 15(1), 110-125.

Seo, S. H. (2015). Study on attentiveness and sentence comprehensive faculty along with old men's hearing loss degree (unpublished master's thesis). Daegu University, Daegu.

Shin, E. Y. (2011). (A) model study of aural rehabilitation program for presbycusis through the analyses of Korean standardized values of the hearing handicap (unpublished doctorial's thesis). Hallym University, Chuncheon.

Shin, J. E. (2013). Rehabilitation of age-related hearing loss patients. Korean Journal of Otolaryngology-Head and Neck Surgery, 56(8), 475-481.

Shin, M. S. \& Huh, M. J. (2011). Auditory functional pattern in terms of ages among senior citizens. Journal of Speech-language and Hearing Disorder, 20(2), 178-185.

The Korean Audiology Society. (2015). Speech Perception Test in Practice. (pp. 187-189). Seoul: Hakjisa.

Weinstein, B. E. (1997). Outcome measures in the hearing aid fitting/selection process. Trends in Amplification, 2(4), 117-137.

Woo, H. C. (1999). Difference in speech discrimination \& preference of sound quality using compression hearing aids (unpublished master's thesis). Yensei University, Seoul. 